\title{
THE PROSPECTS, IMPACTS, AND RESEARCH CHALLENGES OF ENHANCED CELLULOSIC ETHANOL PRODUCTION: A REVIEW
}

\author{
S. L. Ezeoha ${ }^{1,}{ }^{*}$ C. N. Anyanwu' ${ }^{2}$ and J. N. Nwakaire ${ }^{3}$ \\ 1,2,3 Dept of Agricultural and Bioresources EngineERING, Univ. OF Nigeria, NSUKKA, ENUGu STAte, NigERIA \\ E-mail addresses:1 sunday.ezeoha@unn.edu.ng, 2 cosmas.anyanwu@unn.edu.ng, \\ 3 joel.nwakaire@unn.edu.ng
}

\begin{abstract}
The benefits and impacts of enhanced cellulosic ethanol (CE) production, the major features of existing production processes, and some current research challenges of major pretreatment processes are presented. The prospects of enhanced CE production, especially in developing economies like Nigeria are highlighted. We conclude that in order to reap the promising prospects and conquer the challenges and negative impacts of enhanced CE production, current researches for production of cellulosic ethanol must be focused on the development of processes that are capable of liberating and fermenting lignocellulose into bioethanol at faster rates, higher yields, and overall technical and economic efficiency. These researches should concentrate on the development of cheaper enzymes, genetically engineered microorganisms, and cost-effective thermochemical processes in order to accomplish the much-needed breakthrough in cellulosic biofuel production. Properly targeted innovative researches on cellulosic ethanol production processes are the sure route to effective reduction of global dependence on nonrenewable fossil fuels. The needed research breakthroughs will obviously be based on innovative integration of processes rather than on the improvement of the well-known individual processes of bioethanol production.
\end{abstract}

Keywords: Cellulosic ethanol, biofuel, research challenges, cellulolysis, fermentation, lignocelluloses

\section{INTRODUCTION}

There are currently world-wide efforts to reduce global dependence on fossil fuels. The reasons include rising cost of petroleum products, rising energy demands, fear of fossil fuel exhaustion and the need to lower greenhouse emission. There is therefore an increasing search for renewably sourced feedstocks for biofuel production. Biofuels are fuels produced from renewable resources, namely: energy crops, crop residues, forest and waste biomass. Thus, biofuels include fuels that have been used for millennia, like fuel wood and charcoal, as well as newer fuels like ethanol, methanol, biodiesel, and biogas [1]. At present, ethanol is the most trusted common alternate fuel representing a sustainable substitute for gasoline in passenger cars [2]. Ethanol production from first generation biomass resources competes with food supply especially in developing economies. Biomass is the most important of the renewable energy forms in terms of its current and projected consumption on a world scale. It ranks fourth on importance as an energy source with only oil, coal, and gas contributing more energy to the world [3]. Unfortunately, the ability of the biosphere to provide more bioenergy as primary energy is limited, especially if population growth-driven demand for food and fibre products is on the high increase. A solution to the low efficiency in the use of biomass for combustion is the development and manufacture of better wood stoves for developing economies. But, a more rational solution is to focus on improvement in efficiency of biomass production and utilization. And, since food and feed application are essential to human survival, attention must be focused now on the utilization of lignocellulosic materials which include residues and wastes associated with first generation biomass production and processing [3].Interestingly, research has shown that cellulosic ethanol or bioethanol from lignocellulosic plant materials can be produced. However, enhanced (i.e. widespread and commercial scale) cellulosic ethanol (CE) production has not been achieved. In order to arrive at this desired stage, it was considered very important to examine the prospects, impacts, and research challenges of enhanced CE production.

This paper, therefore, presents condensed vital information on the possible benefits, environmental and economic impacts, major features and limitations of existing production processes, and research challenges of enhanced CE production. Some necessary areas of 


\section{The Prospects, ImpaCts, ANd Research Challenges of ENhanCEd CELlulosic EThanol Production S. L. Ezeoha et al}

research needs for enhanced CE production are recommended to serve as pointers for policy makers and researchers in any developing economies like Nigeria that may be intending to venture into large scale bioethanol production.

\section{BENEFITS OF ENHANCED CE PRODUCTION}

In contrast with starch and sugar-ethanol, cellulosic ethanol (CE) is produced from wood, grasses or the inedible parts of plants. Production of bioethanol from lignocellulose has the advantage of abundant and diverse raw materials compared to sources such as food crops but requires a greater amount of processing to make the sugar monomers available to the microorganisms typically used to produce ethanol by fermentation. Energy crops (cellulosic biomass) is cheaper to produce than food crops because it requires fewer inputs, such as energy, fertilizer, herbicides, and other chemicals that can even pose risks to wild life. Its cultivation and utilization has several accompanying benefits or advantages. Non-fermentable and unconverted solids left after producing cellulosic ethanol can be combusted to provide the fuel needed to operate the conversion plant and generate electricity. Cellulose is not used for food and can be grown in all parts of the world. The entire plant can be utilized when producing CE. Herbaceous energy crops reduce soil erosion by greater than $90 \%$ when compared to conventional food crop production [4]. This can translate into improved water quality for rural communities. Compared to food crops production, cellulosic biomass (energy crops) reduces surface runoff and nitrogen transport. Corn-based ethanol provides $26 \%$ more energy than it requires for production while cellulosic ethanol provides $80 \%$ more energy $[5,6]$. Cellulosic ethanol thus yields more energy than is required to grow and convert cellulosic biomass $[5,6]$. The price per ton of CE raw materials is lower than that of grains or fruits. Also, since cellulose is the main component of plants, the whole plant can be harvested which results in much better yields per hectare. CE raw materials are plentiful. In general, cellulosic ethanol production materials are grouped as: crop residues (cane bagasse, corn stover, wheat straw, rice straw, rice hulls, barley straw, sweet sorghum bagasse, olive stones and pulp, etc.); hard wood (aspen, poplar, silver naple, sycamore, black locust, sweet gum, etc.); soft wood (pine, spruce, etc.); herbaceous sp. (switch grass, weeping lovegrass, service a lespedeza, reed canary grass, flat pea hay, etc.); cellulose wastes (news prints, waste paper, recycled paper, etc.) and municipal solid wastes (MSW), $[7,8,9,2]$. All these materials contain cellulose which can be transformed into cellulosic ethanol. Forest biomass has advantages over herbaceous biomass in terms of less ethanol conversion difficulties and higher ethanol yields. Forest biomass also has high density which positively affects transportation costs. It can also be harvested year round which eliminates long term storage. The close to zero ash content of forest biomass reduces dead load in transportation and processing. Forest biomass is, however, more recalcitrant to convert into ethanol than food crops biomass. Cellulosic ethanol materials otherwise called lignocellulosic materials consist primarily of three components viz: cellulose (40-50\%), hemicellulose (20-30\%), and lignin (20-30\%), [10, 2]. Cellulose consists of high molecular weight polymer (long chains) of glucose rigidly held together as bundles of fibres. Hemicellulose is shorter polymers of various sugars (glucose, hexose, and pentose) that bind cellulose bundles together. Lignin consists of tri-dimensional polymer of propyl-phenol that is imbedded in and bound to hemicellulose to provide rigidity [2]. Many lignocellulosics have different physico-chemical characteristics. Food crop residues and hard woods have low lignin and high pentose content compared to soft woods [2]. Strong crystalline structure of cellulose in rice straw, and the complex structure of lignin, hemicellulose and cellulose limit accessibility of straw to enzymatic hydrolysis [2]. Forest products and mill residues typically have higher cellulose and lignin contents and lower hemicellulose and ash content than herbaceous biomass [11].

\section{IMPACTS OF ENHANCED CE PRODUCTION}

Enhanced CE production possesses some impacts. The environmental and economic impacts are presented below:

\subsection{Environmental Impact}

Reduction of the disposal of solid organic wastes via CE conversion would reduce solid waste disposal costs by local and state governments. In comparison to gasoline, ethanol burns cleaner, thus putting less carbon dioxide and overall pollution in the air [12]. CE reduces greenhouse emission by $90 \%$ when compared to gasoline and in comparison to corn-based ethanol which decreases emissions by 10 to $20 \%$ [5]. Ethanol produced from corn has a 'net climate warming' effect when compared to oil if the full lifecycle assessment properly considers the nitrous oxide $\left(\mathrm{N}_{2} \mathrm{O}\right)$ emissions that occur during corn-ethanol productions. Crops with less Nitrogen demand such as cellulosic plants have more favourable climate impacts [13]. Row cropping system has certain negative effects on wildlife. And most commercial production of food crops is done using this system. Therefore, increasing bioethanol production from food crops could accentuate these negative effects on wildlife. On the contrary, the extensive roots of cellulosic biomass plants (which are never planted in rows) help to improve soil quality, reduce erosion, and increase nutrient capture. Herbaceous energy crops add 
organic matter to depleted soils and can increase soil carbon which can have a direct effect on climate change, as soil carbon can absorb carbon dioxide in the air $[4$, 14].

\subsection{Economic Impact}

Enzymes that destroy plant cell tissue cost 10 to 40 cents per gallon of ethanol compared to 3 cents per gallon for corn [15]. Start-up costs for pilot scale CE plants is about $\$ 7 /$ annual gallon production capacity. Corn-to-ethanol plants costs about $\$ 1-\$ 3 /$ annual gallon capacity [16]. The estimates made by the National Renewable Energy Laboratory (NREL), in the US show that bioethanol production cost could range from $\$ 0.30$ to $\$ 0.38 / \mathrm{L}$, depending on the technology utilized and availability of low cost feed-stocks [17, 2]. In Brazil, the average cost of bioethanol production from sugar cane is $\$ 0.22 / \mathrm{L}$ from which about $60 \%$ is the cost of feed stocks [18]. CE has great potential due to widespread availability, abundance and relatively cheap lignocellulosic materials. However, although several CE processes are technically feasible, finding cost-effective processes remains the most vital research issue [19]. Notably, the expansion of bioethanol industry is capable of creating a noticeable increase in job opportunities for both skilled and unskilled workers [12].

\section{FEATURES OF CELLULOSIC ETHANOL PRODUCTION PROCESSES}

The conversion of lignocellulosics to ethanol is generally more complex compared to sugar fermentation and starch hydrolysis/fermentation due to the presence of various amount of other sugars such as xylose and arabinose [2]. Lignocellulosic materials generally contain up to $75 \%$ cellulose and hemicellulose which cannot be easily converted to simple monomeric sugars due to their recalcitrant nature [20]. Lignocellulosics resist degradation and offer hydrolytic stability and structural robustness mainly due to cross linking between polysaccharides (cellulose and hemicellulose) and lignin via ester and ether linkages. Cellulose and hemicellulose are densely packed by layers of lignin that offer protection against enzymatic hydrolysis [9]. As a result of the recalcitrant nature of lignocellulosics there are two approaches to $\mathrm{CE}$ production which include the biochemical and the thermochemical approaches.

\subsection{Biochemical Approach:}

The stages to produce CE using the biochemical approach are: pretreatments, cellulolysis (cellulose hydrolysis), and separation of sugars from lignin, microbial fermentation of the sugars, distillation, and dehydration [21].

\subsubsection{Pretreatments:}

This refers to the solubilization and separation of one or more of the four major components of biomass cellulose, hemicellulose, lignin, and extractives in order to make the remaining solid biomass more accessible to further chemical or biological treatment $[2,22]$. Pretreatment of lignocellulosics aims to decrease crystallinity of cellulose, increase biomass surface area, remove hemicellulose, and break the lignin barrier. Pretreatment makes cellulose more accessible to hydrolytic enzymes to facilitate conversion of carbohydrate polymers into fermentable sugars in a rapid way with the concomitant more yields. Pretreatments include physical, chemical, and thermal methods, and their combinations. Pretreatment is one of the most expensive processing steps for the production of ethanol from biomass [9]. In fact, the pretreatment of cellulosic and lignocellulosic materials for the production of bioethanol has been a major limitation in the commercialization of lignocellulosic ethanol [23]. Physical pretreatments break down the feedstock size by milling or aqueous/ steam processing. Methods used for cellulosic materials require intense physical pretreatment such as uncatalyzed steam explosion (USE) and liquid hot water (LHW).

USE refers to a process where water is the sole reagent. Under high pressure, water acts as an acid causing autohydrolysis of the hemicellulose and the hydrolysis of acetyl groups generate acetic acid with close proximity to the substrate, causing catalysis [24]. Basically, the method consists of heating the material with highpressure steam $\left(20-50\right.$ bar, $\left.210-290^{\circ} \mathrm{C}\right)$ for a few minutes; the reaction is then terminated by sudden decompression to atmospheric pressure [2]. The holding temperature and pressure promotes autohydrolysis while termination by rapid decompression causes the expansion of cellulose fibrils, causing physical disruption and rupturing of the glucose chains [25, 24]. Steam explosion method of pretreatment gives xylose sugar recoveries of between 45 to $64 \%$ [26].

LHW operates with water held in a superheated state (with temperature between the boiling point and the critical temperature of $374^{\circ} \mathrm{C}$ at pressure above 22MPa); where the distinction between liquid hot water and steam disappears. Typical operating temperature range is $180-230^{\circ} \mathrm{C}$ and pressure of $27.6 \mathrm{MPa}$ before quenching (rapid cooling) to end the reaction. The action of the combined high temperature and pressure allows the penetration of the lignin and hemicellulose with water acting as an acid. The chemical degradation of the lignocellulosic materials occurs via three distinct processes namely oxidation, dehydration and pyrolysis. LHW method gives 88 to $95 \%$ xylose recovery which cancels out further need for supportive chemical treatment. Some chemical pretreatment methods include 
ozonolysis, ammonia fibre/freeze explosion, alkaline hydrolysis, and carbon dioxide explosion.

Ozonolysis is based on a system where ozone gas $\left(\mathrm{O}_{3}\right)$ is passed through a reaction vessel containing the substrate. Ozone is known to be highly reactive to functional groups with high electron densities and double $(\mathrm{C}=\mathrm{C})$ bonds. Thus lignin which has a greater incidence of conjugated double bonds reacts mostly with ozone [24]. Ozonolysis produces mainly carboxylic acid groups such as formic acid, oxalic acid, acetic acid, etc., all of which can be metabolized by ruminants [27]. The constraint of ozonolysis is the production of ozone in sufficient quantities and its rapid degradation to oxygen [24]. Ozonolysis is used as a treatment process to wood stocks for cattle feeds. It is also used in the paper pulping /bleaching industries to cause delignification of the paper leaving a whiter finish without compromising the paper strength by breaking the cellulose fibres.

Ammonia fibre/freeze explosion (AFEX) is an alkaline process where lignocellulosic materials are subjected to anhydrous ammonia under elevated temperatures and pressure with quenching through decompression. AFEX is advantageous for low lignin-content herbaceous and agricultural residues with little production of inhibitory products [25]. AFEX also has the benefit of reduced downstream processing prior to fermentation. The drawback of AFEX is the loss of efficiency with high lignin-content materials and the difficulty in solubilizing smaller fractions such as hemicellulose [28]. As AFEX does not directly cause hydrolysis but allows the easing of enzymatic hydrolysis, through the use of the AFEX method reduction in enzyme requirement is achieved. In alkaline hydrolysis, an alkali e.g. lime $\left(\mathrm{Ca}(\mathrm{OH})_{2}\right.$ or sodium hydroxide $(\mathrm{NaOH})$ acts directly as a swelling agent to swell the biomass, increasing the surface area and opening up the structure for water to migrate into the material [29]. Once inside the material the water disrupts the hydrogen bonding between the hemicellulose and the lignin, resulting in the decrease in crystallinity and lignin disruption [30].The advantages of using alkali over acidic methods are the milder conditions (near or at atmospheric pressure and low temperature) and the removal of the lignin fraction without degradation of other major constituents. The demerits include increased reaction times (hours or days compared to minutes for other methods) and the limitation of salt formation and incorporation into the biomass [23].Carbon dioxide $\left(\mathrm{CO}_{2}\right)$ explosion or hydrolysis operates in a similar way to liquid hot water hydrolysis in the manner of using supercritical fluid (SF) for solvent extraction. With $\mathrm{CO}_{2}$ being acidic under high pressures, the mechanism of degradation is similar to LHW and USE [30].

\subsubsection{Cellulolysis}

Cellulolysis means hydrolysis of cellulose and hemicellulose. There are two major cellulolytic processes namely, chemical cellulolysis and enzymatic cellulolysis. Under chemical cellulolysis, either dilute acid is used at high temperature (above $200{ }^{\circ} \mathrm{C}$ ) and high pressure (above atmospheric) or concentrated acid is used at lower temperature (about $100{ }^{\circ} \mathrm{C}$ ) and atmospheric pressure. Dilute acid processes have shorter reaction times (in seconds or minutes) which facilitates continuous processing. Size reduction of the feedstock is important here to allow adequate acid penetration and ensure rapid continuous processing. The sugar conversion efficiency of this method is limited to about 50 percent, mainly because of the simultaneous conversion of the sugar being produced to degradation products like furfural and hydroxymethyl furfural which are also toxic to fermentation microorganisms. The combination of acid, high temperature and pressure dictate special reactor materials which can increase production costs [19, 31, and 32]. The concentrated acid process has a disadvantage of longer reaction times (in several hours), but has an advantage of high sugar recovery (above 90 percent) from both cellulose and hemicellulose. The low temperatures and pressures of this process, however, allow for the use of such reactor and piping materials as fiberglass which is relatively inexpensive [19]. Under enzymatic cellulolysis, cellulose and hemicellulose chains are broken down into glucose molecules by cellulase enzymes at relatively mild conditions $\left(50{ }^{\circ} \mathrm{C}\right.$ and $\left.\mathrm{pH} 5\right)$ without the formation of toxic degradation by-products capable of inhibiting enzyme or follow-up fermentation activities. A pretreatment step is required for the effectiveness of enzymatic hydrolysis. Generally, ethanol yield by enzymatic hydrolysis is governed by many factors which include type of substrate pretreatment, presence of inhibitors, thermostability of enzymes, effect of medium $\mathrm{pH}$, enzyme concentration, enzyme adsorption on substrate surface, duration of hydrolysis, substrate concentration and rate of agitation of medium [2].

\subsubsection{Separation of Sugars}

In this stage, the sugars produced through cellulolysis are separated from residual cellulose and lignin. The recovered sugars are kept for fermentation while the residuals can be used as boiler fuel for steam production and electricity generation.

\subsubsection{Microbial Fermentation of Sugars}

The nature of carbohydrates in lignocellulosic biomass is complex because of the presence of both six-carbon and five-carbon sugars including glucose, xylose, mannose, galactose, and arabinose. Conventionally, baker's yeast (Saccharomyces cerevisiae) is used to produce ethanol 
from hexoses (six-carbon sugars). Unfortunately, this yeast finds it difficult to ferment pentoses (five-carbon sugars). Consequently, the ability of any fermenting microorganism to utilize the whole range of available sugars in a lignocellulosic hydrolysate is vital for increasing the economic competitiveness of cellulosic ethanol production. This area invariably is currently a critical area of research. After microbial fermentation of sugars to ethanol, the distillation process is used to remove water and produce roughly $95 \%$ pure ethanol. Finally, a dehydration process is employed to realize over $99.5 \%$ concentrated ethanol if required.

\subsubsection{Integrated Processes}

Individual steps for converting biomass to ethanol can be implemented separately. But, these steps can otherwise be combined in various ways to form integrated processes aimed at minimizing cost. Two of such processes are described below.

\section{(i) Separate hydrolysis and fermentation (SHF) process} In this method starch or lignocellulose hydrolysis and sugar fermentation are differently handled. Starch molecules are hydrolyzed by $\alpha$-amylase (an amyloptic enzyme) and by gluco-amylase. The $\alpha$-amylase does the liquefaction job while the gluco-amylase saccharifies the substrate, but all in the same reactor compartment. Unfortunately, sugar-inhibition of $\alpha$-amylase activity occurs here which affects ethanol yield negatively. After the completion of the hydrolysis and saccharification process, fermentation of the substrate is achieved separately using saccharomyces cerevisiae [33].

\section{(ii) Simultaneous saccharification and fermentation (SSF) process}

In this process, starch molecules are initially hydrolyzed by $\alpha$-amylases and cellulose by cellulases. Then the sugars released are saccharified and fermented simultaneously by concomitant addition of glucoamylase and yeasts in one common reactor. Here, the problem of sugar-inhibition found with SHF is highly minimized because of the joint action of the yeasts and the gluco-amylase in one reactor or compartment that is separate from the action zone of the sugar-susceptible $\alpha$ amylase. And this tends to improve the ethanol yields of SSF. Using this method, yellow poplar (a hardwood) feedstock was pretreated with cellulase at $15 \mathrm{FPU} / \mathrm{g}$ at 30 ${ }^{\circ} \mathrm{C}$ for 7 days to produce c.a 250litres /ton of cellulosic ethanol [17]. Also, corn stover was also pretreated with cellulase at $65 \mathrm{FPU} / \mathrm{g}$ at $40{ }^{\circ} \mathrm{C}$ for 4 days to generate CE concentration of $25 \mathrm{~g} / \mathrm{L}$ [34].

\subsection{Thermochemical Approach}

This approach does not rely on decomposition of cellulose chains. Rather, the carbon in the lignocellulosic feedstock is converted to synthesis gas by incomplete combustion (gasification). The hydrogen and carbon oxides (synthesis gas) produced are then fed into special fermenters where appropriate microorganisms are used to convert the gas into ethanol in a process of fermentation [19]. Alternatively, the synthesis gas produced is fed into a catalytic reactor where the gas is converted to ethanol and other higher alcohols and liquid fuels [35]. Finally, the ethanol produced in either case is purified via processes of distillation and dehydration.

\section{RESEARCH CHALLENGES OF ENHANCED CE PRODUCTION}

These challenges are presented here under three subheadings namely: pretreatment processes, cellulolysis and fermentation processes, and thermochemical systems.

\subsection{Pretreatment Processes}

Lignocellulosic feedstock consists of lignin, cellulose, and hemicellulose. Lignin which contains no sugar encloses the cellulose and hemicellulose molecules. Like starch, cellulose consists of long chains of glucose molecules; but unlike starch, cellulose has structural features which coupled with its encapsulation by lignin makes it more difficult to be hydrolyzed. Hemicellulose contains long chains of glucose molecules (6-carbon sugars) plus 5carbon sugars in varying proportions depending on its source. The research needs for enhanced CE production therefore include developing processes or methods capable of liberating, reducing, and fermenting lignocellulosic feedstocks into ethanol at faster rates, higher yields and overall efficiency both technically and economically. Lignocellulosic materials require more drastic hydrolysis steps to achieve high ethanol conversion yields because of the presence of various amounts of 5-carbon sugars like xylose and arabinose. The most costly aspect of producing bioethanol from lignocellulosic materials is pretreatment to make them accessible to the enzymes or chemicals that will cut the sugars from the polymers before fermentation to ethanol [36]. The following pretreatment processes are highlighted: acid-catalyzed systems, alkaline systems, ozonolysis, ammonia-fibre/freeze explosion, $\mathrm{CO}_{2}$ explosion, uncatalyzed steam explosion, liquid hot water, and microwave oven heating systems.

\subsubsection{Acid-catalyzed Pretreatment Systems}

Dilute acid systems give low yield of fermentable sugars from cellulose and hemicellulose $(50-60 \%$ of the theoretical yield). Concentrated acid or halogen acid systems give higher sugar yields (up to $100 \%$ of the theoretical yield) but utilize large amounts of low cost acids like sulphuric acid $\left(\mathrm{H}_{2} \mathrm{SO}_{4}\right)$ or expensive halogen acids. This situation makes acid recovery through 
recycling an essential aspect of concentrated acid or halogen pretreatment systems. In general, the disadvantages of acid processing are the low sugar yields, high energy consumption due to elevated temperatures and pressure and the requirements of corrosive-resistant materials. The current research needs of acid-catalyzed pretreatment systems therefore include:

(i). Investigation into innovative processes that can overcome the limitations of dilute acid systems which is degradation of pentose sugars from hemicellulose into furfural - a fermentation inhibitor so as to increase the low yield of sugars typical of such systems.

(ii). Development of efficient, low-cost recycling operations for the large volumes of concentrated acids and expensive halogen acids in order to make these systems economical.

\subsubsection{Alkaline Pretreatment Systems}

Sodium hydroxide $(\mathrm{NaOH})$ is the dominant alkali frequently used in this system. But lime $\left(\mathrm{Ca}(\mathrm{OH})_{2}\right)$ is also used as a good alternative. Alkaline pretreatment is effective on hemicellulose and lignin, decreasing crystallinity of hemicellulose and removing lignin [37, 26]. The current research needs of the alkaline pretreatment system therefore include:

(i) Investigation of innovative processes that can reduce the length of long reaction times of alkaline systems from hours and days to minutes or seconds.

(ii) Development of processes that can reduce or overcome the limitations of salt formation and its irrecoverability.

\subsubsection{Ozonolysis}

Ozonolysis is effective on lignin but not on cellulose and hemicellulose. The major constraint of ozonolysis is the production of ozone $\left(\mathrm{O}_{3}\right)$ in sufficient quantities. Also ozone production has to be site specific because of the problem of its rapid degradation to oxygen. The research perspectives of ozonolysis are therefore those of developing innovative methods for achieving high volume production of ozone and reducing the rate of degradation of ozone to oxygen.

\subsubsection{Ammonia Fibre/ Freeze Explosion (AFEX):}

AFEX pretreatment has limited ability to solubilize lignin and hemicellulose. Its increased efficiency is therefore with low lignin content materials like herbaceous and agricultural residues. The need exist therefore for innovative investigation into how to make AFEX effective on lignin and hemicellulose to achieve higher ethanol yields.

\subsection{5 $\mathrm{CO}_{2}$ Explosion}

The research needs of this method of pretreatment include modeling of the system to achieve optimized condition for temperature, pressure, moisture content, and time of treatment.

\subsubsection{Uncatalyzed Steam Explosion}

This pretreatment system is effective on both cellulose and hemicellulose with greatest success on hardwoods and crop residues and reduced effect on softwoods and MSW. Major limitations of USE include low xylose yield and increase in crystallinity of cellulose. Innovative research is required to develop processes that can increase xylose yield of lignocellulosic materials using un-catalyzed steam explosion.

\subsubsection{Liquid Hot Water}

This is effective in degrading both lignin and hemicellulose. The major research perspective has to do with striking a balance between monosaccharide yield and inhibitor formation.

\subsubsection{Microwave Oven Heating}

Microwave oven heating could alter the ultra-structure of cellulose, degrade hemicellulose and lignin to make them more susceptible to enzymatic actions. Microwave achieves this by direct intervention of its target and the electromagnetic field to generate heat. Heating by microwave is both volumetric and rapid when applied to lignocellulosics. Other non-thermal effects of microwave may probably account for its effectiveness [9].

\subsection{Cellulolysis and Fermentation Processes}

A common disadvantage of enzymatic hydrolysis is the end-product inhibition of the enzymes used to hydrolyze cellulose and hemicellulose. This problem can however be reduced by the adoption of SSF or use of immobilized enzymes with a hollow-fibre membrane reactor, in which case the enzymes are confined inside the reactor allowing the separation of substrate and hydrolysis products as well as enabling the reutilization of the enzymes [38]. The adoption of SSF and use of immobilized enzymes, however, creates the need for innovative design of bioreactors for integrated processes.

\subsection{Thermochemical Systems}

Ethanol yields of up to $50 \%$ have been obtained using thermochemical processes [19]. Unfortunately, finding a cost-effective all-thermochemical process has been difficult. This calls for serious research effort towards achieving this end. 


\section{PROSPECTS OF ENHANCED CE PRODUCTION IN DEVELOPING ECONOMIES}

Enhanced CE production offers a number of prospects for development but also pose some challenges, especially in developing economies. The International Energy Agency (IEA) projected that biofuels would be competitive with petroleum at petroleum prices of between US $\$ 60$ and US $\$ 100$ a barrel; and that point was reached as at 2006[1]. This is why biofuel production is generating a lot of interest worldwide. Another reason is that enhanced biofuel production offers a number of prospects which include renewability, enhanced national energy security, and economic growth as a direct consequence of higher energy efficiency and lower cost of production. It also offers environmental sustainability through greenhouse abatement; and again poverty reduction especially among the rural farming population through increased profitable employment [1,39].The efficiency and costs of biofuel production are largely a function of the type of feedstock, the conversion technology used, as well as the agro-ecological and socioeconomic conditions of production of biomass and the use of biofuel [40]. The major challenge to expanding or enhancing biofuel production continues to be whether crop production for biofuels will compete with and drive out food production, thereby increasing food insecurity [41]. The competitiveness of biofuels depends strongly on the relative prices of petroleum and of agricultural feedstocks for biofuel. When the demand for biofuel increases agricultural prices, the competitiveness of biofuels will begin to diminish. The future of biofuel as an important source of carbon neutral renewable energy will lie in reducing the direct competition with the food sector, and instead use feedstock with lower agricultural production costs compared to food and feed crops [1]. Incidentally, it is only cellulosic biofuel production that does not compete strongly with food and feed production, as much of the feedstocks can be supplied by the forestry sector from non-arable land or from byproducts of the agricultural sector. Generally, energy crop production may not lead to increased food insecurity if food crop residues only are utilized for biofuel, energy crops are cultivated on marginal or degraded lands only, farmers rotate food and energy crops on the same lands, crop productivity is increased through research; and if enhanced biofuel production can raise incomes of small farmers and rural labourers in developing economies. Policy makers should ensure that the possible pitfalls of biofuel production are avoided. These pitfalls include negative energy balance, insignificant reduction in greenhouse gases compared with petroleum, socio-economic inequalities by concentrating benefits on the rich, deforestation, loss of biodiversity, excessive use of fertilizer and chemicals which can degrade the land and water that poor people depend on[1]. As more and more nations set standards and targets for use of biofuels, they should ensure that poor peoples and small farmers participate gainfully from the energy system. Because biofuel production is as labour intensive as agriculture, it may be a boom to rural communities with surplus labour.

In summary, as the potential for producing cost-effective cellulosic ethanol that uses plentiful and sustainable cellulosic plant biomass continues to grow, the prospects of enhanced CE production for developing economies will depend on available size of agricultural land, appropriate climate for growth of cellulosic plant biomass, integrated products approach, level of processing technology in use, ability to take advantage of synergies between bioethanol production, electricity, and heat production. It will also depend on institutional and government support and policies.

\section{CONCLUSION AND RECOMMENDATIONS}

1. In conclusion, there is urgent need to develop new technologies capable of increasing efficiency and productivity in crop production and biofuel processing. In developing economies public-private partnership can work to increase farmers awareness of opportunities being presented by biofuel production and the potential benefits. What will actually make enhanced CE production a win-winaffair for poverty reduction and energy production on one side, the environment and the economy on the other side, include sound technological innovation, appropriate government policies and support, and sound institutional innovations.

2. Pretreatment of cellulosic and lignocellulosic biomass in a cost-effective manner is a major research and development challenge for enhanced cellulosic ethanol production.

3. There is need for research to address the issues of low sugar yields and high energy consumption of acid pretreatment processes.

4. If less costly enzymes can be developed through research, enzymatic processes possess several advantages which include: high efficiency, controllable production by-products, mild process conditions, less-expensive reaction vessels, and relatively low process energy.

5. Research is seriously needed to create super microorganisms that will enhance the adoption of direct microbial conversion (DMC) for CE production.

6. Increased research effort is advocated to develop genetically engineered fungi which can produce large volumes of cellulase, xylanase, and hemicellulose enzymes that can be used to convert agricultural residues into fermentable sugars. 
7 Genetic engineering of plants is another promising research area via which starch content of crops and plants could be increased for enhanced yield of bio ethanol.

8 Cellulosic ethanol researchers in developing nations need to conduct research on their national $\mathrm{CE}$ feedstocks availability and production potential.

9 Biochemical research should investigate pretreatment, hydrolysis, fermentation steps, process integration and biomass proximate analysis.

10 .Thermochemical research should investigate catalyst and process development, and process analysis.

11 Research is important to investigate potentially cheaper, but still effective pretreatment methods; to apply knowledge of biomass structural changes to pretreatment process development; and to investigate proper enzyme mixture for enhanced hemicellulose hydrolysis.

12 There is also need to investigate into more causes of cellulosic biomass recalcitrance and more and better ways to overcome it.

13 Research on biomass rheology is very critical for providing process engineers with rheological information needed to design commercial biorefineries.

14 The need exists also to characterize plant structure using state of the art capabilities so as to develop superior enzymatic hydrolysis processes.

15 Research should also be carried out to determine whether using a high ratio of biomass to water in the bio-refining process can be a way to cutting CE production costs; and also the potential problems of high biomass water ratio.

16 Technology has not yet developed to allow the processing of a mixture of different grass species or vegetation types to bioethanol. Innovative research is therefore critically needed to develop mixed vegetation processes for CE production.

17 There is need for establishment of companies that can build industries or refineries based on different methods of converting lignocellulosic organic matter into biofuel; and companies that can produce enzymes at competitively low cost and in commercial quantities for the CE refineries. These needs can only be realized through concerted research efforts.

\section{REFERENCES}

[1] Braun J. and Pachauri, R. K. "The promises and challenges of biofuels for the poor developing countries", Doi: http://dx.doi.org/10.2499/0896299147 www.ifpri.org $>$ Booklets $>$ Essays, Accessed on Dec. 17, 2014. 2006.
[2] Neves, M. A., Kimura, T., Shimizu, N. and Nakajima, M. "State of the art and future trends of bioethanol production", Dynamic Biochemistry, Process Biotechnology and Molecular Biology 1 (1), pp. 1-14, 2007.

[3] Overend, R. P. "Biomass for Energy", Energy Studies Review 1(1), pp 16-26. 1989.

[4] Nelson, R. "Cellulosic ethanol: bioethanol in Kansas", http://kec.kansas.gov/reports/Cellulosic_Ethanol_FINAL. pdf, Accessed on Oct. 22, 2014. 2007.

[5] Montenego, M. "The Big Three", Grist Environmental News. http://grist.org/article/montenegro/_Accessed on Dec. 10, 2014. 2006.

[6] Ratlif, E. "One molecule could cure our addiction to oil", Wired Magazine 15(10), https://www.wired.com/2007/09/ff-plant/, Accessed on January, 12, 2016. 2007.

[7] Wikipedia "Cellulosic ethanol", en.wikipedia.org/wiki/cellulosic _ethanol, Accessed on April 22, 2013.

[8] Oscar, J. S. and Carlos, A. C. "Trends in biotechnological production of fuel ethanol from different feedstock", Bioresource Technology, 99, pp. 5270-5295, 2008.

[9] Verma, A. S. Kumar and P. K. Jain "Key pretreatment technologies on cellulosic ethanol production", Journal of Scientific Research (Banaras Hindu University, Varanasi). http://www.bhu.ac.in/journal/Issues/JournalofScientifc ResearchVol55/6.\%20AMRITA\%20PAPER.pdf,_Accessed on August 03, 2014. 2011.

[10] Ehara, K and Saka, S. "A comprehensive study on chemical conversion of cellulose between the batch-type and flowtype systems in supercritical water", Cellulose, 9, pp. 301311,2002

[11] National Renewable Energy Laboratory (NREL). "Cellulosic ethanol", Publication No. NREL/BR-51040742. http://www.nrel.gov/biomass/pdfs/40742.pdf, Accessed on Nov. 17, 2014. 2007.

[12] Nwakaire J. N., Ezeoha, S. L. and Ugwuishiwu, B. O. "Production of cellulosic ethanol from wood sawdust", Agric Engineering International: CIGR Journal, 15(3), pp 136-140, 2013.

[13] Crutzen, P. J., Mosier, A. R., Smith, K. A. and Winiwarter, W."Nitrous oxide release from agro-biofuel production negates global warming reduction by replacing fossil fuels", Atmospheric Chemistry and Physics, 8(2), pp. 389395, 2008.

[14] Charles, W. R. "Storing carbon in soil: why and how?"http://www.geotimes.org/jan02/feature carbon.ht $\mathrm{ml}$, Accessed on Nov. 10, 2014. 2002.

[15] Klein-Marcuschamer, D., Oleskowicz-Propiel, P., Simmons, B. A., Blanch, H. W. "Technoeconomic analysis of biofuels: A wiki-based platform for lignocellulosic biorefineries", Biomass Bioenergy, 34, pp. 1914-1921, 2010.

[16] United States Department of Energy (DOE). "Feasibility study for co-locating and integrating ethanol production plants from corn starch and lignocellulosic feedstocks",http://www.nrel.gov/docs/fy050sti/37092.p df, Accessed on Nov. 12, 2014. 2005.

[17] Wooley, R., Ruth, M., Glassner, D. and Sheenan, J."Process design and costing of bioethanol technology: a tool for 


\section{The Prospects, ImpaCts, ANd Research Challenges of ENhanCEd CELlulosic EThanol Production S. L. Ezeoha et al}

determining the status and direction of R\&D", Biotechnology Progress,15, pp. 794-803, 1999.

[18] Daishou, Y. "Baietanooru saizensen", Kougyou Chyouskai, ' Tokyo, 253pp (in Japanese) (Cross ref.) 2004.

[19] Badger, P. C. "Ethanol from cellulose: A general review", In: J. Janick and A. Whipkey (eds.), Trends in new crops and new uses, p. 17-21 (ASHS Press, Alexandria VA). large.standford.edu/publications/coal/references/docs/ badger.pdf. Accessed on Dec. 20, 2014. 2002.

[20] Begun, M.F. and Alimon, A. R. 'Bioconversion and saccharification of some lignocellulosic wastes by Aspergillus oryzae ITCC-4857.01 for fermentable sugar production.' Microbial Biotechnology 14 (5). DOI: 10.2225/vol14-issue5-fulltext-

3.http://www.ejbiotechnology.info/index.php/ejbiotechn ology/article/view/v14n5-3/1355, Accessed on Dec. 18, 2014. 2011.

[21] Zhu, J. Y., Pan, X. J. Wang, G. S. and Gleisner, R."Sulfite pretreatment (SPORL) for robust enzymatic saccharification of spruce and red pine", Bioresource Technology, 100(8), pp. 2411-2418, 2009. Doi:10.1016/j.biortech.2008.10.10.057.PMID19119005.

[22] Mosier N., Wyman, C., Dale, B. E., Elander, R., Lee, Y. Y., Holtzapple, M. and Ladisch, M. 'Features of promising technologies for pretreatment of lignocellulosic biomass,' Bioresource Technology 96:673-686. http://dx.doi.org/10.1016/j.biortech.2004.06.025. 2005.

[23] Balat, M. "Progress in bioethanol processing", Progress in Energy and Combustion Science, 34(5), pp. 551-573, 2008..

[24] Stavrinides, A. J., Phips, D. A. and Al-Shamma'a, A. "Review; Current and developing lignocellulosic pretreatment methods for bioethanol production",https://www.limu.ac.uk/BLT/BUE_Docs/Am ended_PROCEEDINGS_BEAN_2010_WEB_VERSION_24.pdf Accessed on Oct.. 11, 2014. 2010.

[25] Sun, Y. and Cheng, J. "Hydrolysis of lignocellulosic materials for ethanol production: a review", Bioresource Technology, 83(1), pp. 1-11, 2002.

[26] Hammelinck, C. N., Hooijdonk, G. V. and Faaij, A. P. C. Prospects for ethanol from lignocellulosic biomass: Techno-economic performance as development progresses (Universiteit Utrecht, Copernicus Institute). 2003.

[27] Vidal, P. F. and Molinier, J. "Ozonolysis of lignin Improvement of in vitro digestibility of poplar sawdust:, Biomass, 16(1), pp. 1-17, 1988.

[28] Hayes, D. J. "An examination of biorefining processes, catalysts and challenges", Catalysis Today, 145, pp. 138$151,2009$.

[29] Kosaric, N. and Vardar-Sukan, F. "Substrates for industrial alcohol production", The Biotechnology of Ethanol.
biology.krc.karelia.ru:8080/.../The\%20Biotechnology\%2 0of\%20 Ethanol...Accessed on Nov. 22, 2014. 2001.

[30] Kim, K. H. and Hong, J. "Supercritical $\mathrm{CO}_{2}$ pretreatment of lignocellulose enhances enzymatic cellulose hydrolysis", Bioresource Technology, 77(2), PP. 139-144, 2001.

[31] Oregon Cellulose Ethanol Study. 'Appendix B: Overview of Cellulose Ethanol Production Technology,' www.oregon gov/energy/renew/biomass/docs/oces/oces_b.pdf, Accessed on Sept. 04, 2014.

[32] Palmqvist, E. and B. Hahn-Hagerdal 'Fermentation of lignocellusic hydrolysates. 1: Inhibition and detoxification,' Bioresource Technology, 74, pp. 17-24, 2000

www.sciencedirect.com/science/article/pii/S096085249 $\underline{90016012000}$

[33] Mojovic, C., Nikolic, S. Rakin, M. and Vukasinovic, M."Production of bioethanol from corn meal hydrolysates", Fuel, 85, pp.1750-1755, 2006.

[34] Ohgren, K. O. Bengtsson, M. F. Gorwa-Gruslund, M. Galbe, Hahn-Hagerdal, B. and Zacchi, G."Simultaneous Saccharification and co-fermentation of glucose and xylose in steam-pretreated corb stover at high fibre content with saccharomyces cerevisiae TMb3400",Journal of Biotechnology, 126(4), pp. 488-98, 2006.

[35] Power Energy Fuels Inc. "Power Energy Fuels Inc. leads the world in waste-to-ethanol motor fuel conversion",http://www.prnewswire.com/newsreleases/power-energy-fuels-inc-leads-the-world-inwaste-to-ethanol-motor-fuel-conversion82426682.htmlAccessed on Oct. 28, 2014.

[36] Sanderson, K. "US biofuels: A field in ferment", Nature, 444, pp. 673-676. 2006. http://www.nature.com/ nature/journal/v444/n7120/full/444673a.html, Accessed on Sept. 12, 2014. 2006.

[37] DOE "Cellulosic Ethanol: Benefits and challenges",Genomics:GTLhttp://web.archive.org/web/2 0091125175608/http://genomicscience.energy.gov/biof uels/benefits.shtml Accessed on June 06, 2014. 2007.

[38] Cardona, C. A. and Sanchez, O. J. "Fuel ethanol production: process design trends and integration opportunities", Bioresource Technology, 98, pp. 2415-2457, 2007.

[39] Oke, M. A., Annuar, M. S. M. and Simarani. "Mixed Feedstock Approach to Lignocellulosic Ethanol Production-Prospects and Limitations", Bioenerg Res., DOI 10.1007/s12155-016-9765-8, 2016.

[40] Ziolkowska, J. R. "Prospective technologies, feedstocks and market innovations forethanol and biodiesel production in the US", Biotechnology Reports,4, pp. 9498, 2014.

[41] Dilekli, N. and Duchin, F. "Prospects for Cellulosic Biofue Production in the Northeastern United States: A Scenario Analysis", Journal of Industrial Ecology, 20(1) 2015. 